\title{
Study on Neonates who received Exchange Transfusion at Dhaka Shishu Hospital
}

\author{
M Rahman ${ }^{1}$, P K Sarkar ${ }^{2}$, T Nazrin ${ }^{3}$, K Chowdhury ${ }^{4}$, R A Jahan ${ }^{5}$, M S Islam ${ }^{6}$, F Akhter ${ }^{7}$
}

Abstract

Objective : To identify etiology of neonatal hyperbilirubinaemia requiring Exchange Transfusion (ET) and to see the complications of ET and its outcomes.

Methods : This prospective study was done in a tertiary hospital. Total 39 admitted newborn babies with hyperbilirubinaemia who required exchange transfusion were enrolled and all information regarding etiology of jaundice, laboratory investigations, complications and outcomes of cases were documented and analyzed.

Results : During one year of study period ET was done in 39 neonates. Among them $16(41 \%)$ cases were male and $23(59 \%)$ were female. Fifteen $(38 \%)$ babies were preterm and $24(62 \%)$ babies were term. Fifteen (38\%) babies were preterm low birth weight (PLBW) with or without septicaemia as comorbidity. Twelve (31\%) cases had only hyperbilirubinaemia. Rh-incompitability was seen in 17 (44\%), ABO incompitability in $15(38 \%)$ cases and unknown cause in $7(18 \%)$ neonates. Common complications seen were hypoglycaemia in $7(18 \%)$ and thrombocytopenia in $6(15 \%)$ neonates. Two $(5 \%)$ neonates who died had comorbidity.

Conclusion : Exchange transfusion is required mostly in $\mathrm{Rh}$ incompitability and common complications of ET were hypoglycaemia and thrombocytopenia.

\section{Introduction}

Neonatal jaundice is a common phenomenon affecting $60 \%$ of full term and $80 \%$ of preterm babies in first 3 days of life. ${ }^{1-3}$ Most jaundice is benign, but because of the potential toxicity of bilirubin, newborn infants must be monitored to identify those who might develop severe hyperbilirubin aemia and in rare cases, acute bilirubin encephalopathy or kernicterus.

Use of phototherapy, intravenous immunoglobulin has resulted in a decline in the rates of significant neonatal jaundice ${ }^{5}$. When the bilirubin is rising continuously, instead of declining in spite of those measures, to the level that kernicterus is considered a threat, then exchange transfusion (ET) is considered. Although ET is considered a safe procedure, it is not risk free and mortality rates vary from 0.5 to $3.3 \%$. $^{6-9}$

The complications depend on several co-morbid conditions. ${ }^{3}$ The bilirubin level at which exchange transfusion is indicated remains controversial. ${ }^{6}$ This is because it is very difficult to define the risk of bilirubin encephalopathy in various categories of patients. ${ }^{6}$

Current recommendations for performing ET are based on balance between the risks of encephalopathy and the adverse events related to the procedure ${ }^{6}$. The aim of this study is to determine the indication and complications of exchange transfusion (ET) performed in neonatal hyperbilirubinaemia.

Method : This prospective study was conducted in the Neonatal ward of Dhaka Shishu Hospital from January 2011 to December 2011. All neonates who under went ET due to hyperbilirubinaemia during this period were enrolled in the study. Parents were interviewed for a detail history and thorough physical examination was done. The findings were recorded in a structured questionnaire. Information recorded were gestational age, weight of the baby, onset of jaundice and duration, clinical and laboratory data supporting cause of jaundice and any co-morbidities associated with jaundice. Investigations included Complete blood count with peripheral blood film, Reticulocyte count, Blood group of the baby and the mother, Coombs' test (direct and indirect), S(Serum) bilirubin, S. calcium, S electrolytes and Random blood sugar(RBS) in all cases. C-reactive protein, Blood culture and Arterial blood gas analysis were performed when needed. ET was carried out as per hospital protocol without the interference of the researchers. Parents have been explained about the procedure and consents were taken by the duty doctors prior to the procedure. Double volume exchange transfusion was done in a strict aseptic way. After ET, some investigations like Haemoglobin, S. bilirubin, S calcium, S electrolytes and blood glucose were done.

For data analysis, all the data were entered into computer. Statistical analysis was carried out using computer software devised as the Statistical packages for social scientist (SPSS-17).

$A B O$ incompatibility was defined when the newborn with $A$ or $B$ group from mother having $O$ blood group showed evidence of haemolysis and jaundice. Rh incompatibility was defined where jaundice with evidence of haemolysis was seen in the Rh positive baby born to Rh negative mother.

Results : During the study period ET was done in 39 neonates. Among them $16(41 \%)$ were male and $23(59 \%)$ were female. Fifteen (38\%) babies were preterm, $24(62 \%)$ babies were term. (Table I) 
In this study $5(13 \%)$ were PTLBW, $10(26 \%)$ were PTLBW with Septicaemia, 2(5\%) had Septicaemia, 3(8\%) had Perinatal asphyxia, $4(10 \%)$ were Infant of diabetic mother (IDM), 3(8\%) had Congenital heart disease and 2(5\%) had acute bilirubin encephalopathy as comorbidities along with hyperbilirubinaemia. Twelve (31\%) cases came with only hyperbilirubinaemia. (Table II)

Table-I : Baseline characteristics of enrolled neonates $(n=39)$

$\begin{array}{lcc}\text { Nenates } & \text { Characteristics } & \text { No (\%) } \\ \text { Sex } & \text { Male } & 16(41 \%) \\ & \text { Female } & 23(59 \%) \\ \text { Birth weight } & \text { Normal weight } & 23(60 \%) \\ & \text { Low birth weight } & 16(40 \%) \\ \text { Gestational age } & \text { Term } & 24(62 \%) \\ \text { Residence } & \text { Preterm } & 15(38 \%) \\ & \text { Dhaka } & 20(51 \%) \\ & \text { Outside Dhaka } & 19(49 \%)\end{array}$

Tabla-II : Co-morbidity among the cases ( $n=39$ cases)

$\begin{array}{lcc}\text { Co-morbidity } & \text { Number } & \text { Percentage (\%) } \\ \text { PTLBW } & 5 & 13 \% \\ \text { PTLBW with Septicemia } & 10 & 26 \% \\ \text { Septicemia } & 2 & 5 \% \\ \text { Perinatal asphyxia } & 3 & 8 \% \\ \text { Congenital heart disease } & 3 & 8 \% \\ \text { IDM } & 4 & 10 \% \\ \text { Acute bilirubin encephalopathy } & 2 & 5 \% \\ \text { No co-morbidity } & 12 & 31 \%\end{array}$

Among the 39 cases, no causes were identified in $7(18 \%)$ neonates. $\mathrm{ABO}$ incompatibility and $\mathrm{Rh}$ incompatibility were present in $15(38 \%)$ and $17(44 \%)$ case respectively. (Table III)

$\begin{array}{lcc}\begin{array}{l}\text { Table- III : Etiology of Hyperbilirubinaemia among the cases }(\mathbf{n}=\mathbf{3 9}) \\ \text { Etiology }\end{array} & \begin{array}{c}\text { Number } \\ \text { Percentage(\%) }\end{array} \\ \text { ABO incompatibility } & 15 & 38 \% \\ \text { Rh incompatibility } & 17 & 44 \% \\ \text { Unknown } & 7 & 18 \%\end{array}$

Table IV : Complications of exchange transfusion in 15(38\%) neonates Complications

$\begin{array}{cc}\text { Number(n) } & \% \\ 2 & 5 \% \\ 3 & 8 \% \\ 7 & 18 \% \\ 3 & 8 \% \\ 7 & 18 \% \\ 2 & 5 \% \\ 2 & 5 \% \\ 1 & 3 \% \\ 2 & 5 \% \\ 6 & 15 \% \\ 2 & 5 \%\end{array}$

Due to exchange transfusion 15(38\%) babies developed complications. Multiple exchange transfusions were required in 2(5\%) cases. Apnea, Hypothermia and Pumonery haemorrhage were present in $2(5 \%)$, $2(5 \%), 1(3 \%)$ cases subsequently during exchange transfusion. The complications after ET were thrombocytopenia 6(15\%), hyperkalaemia $2(5 \%)$, hypocalcaemia $3(8 \%)$, Hyponatremia $3(8 \%)$, hypoglycaemia $7(18 \%)$ and septicaemia $7(18 \%)$. Two (5\%) babies died after ET due to congenital heart disease and PTLBW with septicaemia. (Table IV)

Discussion : ET has been shown to reduce brain damage in severely jaundiced patients. Simultaneously indications for exchange transfusion in jaundice have changed markedly in the past decade in developed countries, following increased use of rhesus anti D and wide spread used of phototherapy in neonatal jaundice. ${ }^{1}$

During the study period ET was done in 39 neonates. Among them 16 $(41 \%)$ were male and $23(59 \%)$ were female. Fifteen $(38 \%)$ babies were preterm and $24(62 \%)$ babies were term. Hoque et al found in their study that $23(60 \%)$ were male and $15(40 \%)$ were female, $25(66 \%)$ full term and $13(34 \%)$ were preterm babies. ${ }^{3}$ Begum et al, weisz et al and Ekteish et al also found similar results in their study. ${ }^{5,6,8}$

In this study $5(13 \%)$ were PTLBW, $10(26 \%)$ were PTLBW with Septicaemia, 2(5\%) had Septicaemia, 3(8\%) had Perinatal asphyxia, $4(10 \%)$ were Infant of diabetic mother (IDM), $3(8 \%)$ had Congenital heart disease and 2(5\%) had acute bilirubin encephalopathy as comorbidities along with hyperbilirubinaemia. Twelve (31\%) cases came with only hyperbilirubinaemia without co-morbidity.

PTLBW with or without septicaemia were predominant co-morbidity similar to Begum et al and Hoque et al reports. ${ }^{3,6}$ Others studies also found similar results. ${ }^{9,10}$. Among the 39 cases, no causes were identified in $7(18 \%)$ neonates. Others studies demonstrated unidentified cause of hyperbilirubinaemia were more. $\mathrm{ABO}$ incompatibility and $\mathrm{Rh}$ incompatibility were present in $15(38 \%)$ and $17(44 \%)$ cases respectively. Unlike this study where Rh incompatibility was more, Dikshit et el and Sanpavatet al reported that ABO haemolytic disease of newborns was the most common cause of ET in neonates $(35.9 \%$ and $21.3 \%$, respectively). ${ }^{3,6}$ Multiple exchange transfusions were required in $2(5 \%)$ cases. This is similar to findings of Ekteish et al, Begum et al and Dikshit et al reports. ${ }^{3,8,11}$

Apnea, Hypothermia and Pulmonary haemorrhage were present in $2(5 \%), 2(5 \%), 1(3 \%)$ cases subsequently during exchange transfusion. The complications after ET were thrombocytopenia 6(15\%), hyperkalaemia $2(5 \%)$, hypocalcaemia $3(8 \%)$, Hyponatremia $3(8 \%)$, hypoglycaemia $7(18 \%)$ and septicaemia $7(18 \%)$. Similar complications were found in other studies. ${ }^{5,8,10,12-14}$ In the Begum et al study most common complications were thrombocytopenia (33.3\%), hyperkalaemia $(20.0 \%)$ and hypocalcaemia (16.7\%). Badlee $Z$ in his study found that common complications of ET was hypocalcaemia $(29.0 \%)$ and thrombocytopenia (44\%). ${ }^{15}$ Though transient complications are more due to ET but there was also mortality related to ET reported in many studies. In this study 2 (5\%) babies died after exchange transfusion due to congenital heart disease with septicaemia and PTLBW with septicaemia. Similar mortality rate was found in the other studies. In our country Hoque et al and Begum et al found mortality related of ET were $8 \%$ and $3.3 \%$ respectively in their studies. Most of the mortality of ET was related to co-morbidity of cases. 


\section{Conclusion}

Exchange transfusion is required mostly in Rh incompitability and common complications of ET were hypoglycaemia and thrombocytopenia.

\section{References}

1. Bhat AW, Churoo BA, Iqbal Q, Sheikh MA, Javeed Iqbal, Rubina Aziz R Complication of exchange transfusion at a tertiary care hospital. Curr Pediatr Res 2011; 15 (2): 97-99

2. Jain S,Agarwal $R$,Sankar MJ,Akok K,Paul KK,PaulKV.Jaundice in newborns.Indian journal of paediatrics.2008;75(2):157-63

3. Hoque $M_{\|}$, Hossain MM, Hassan MQ, Ahamed ASMNU, Begum J A,Chawdhury MAKA. Neonatal Hyperbilirubinaemia Requiring Exchange Transfusion:Management and Outcome. Bangladesh J Child Health 2004; 28(2): 55-59

4. American Academy of Paediatrics. Clinical practical guideline Subcommittee on Hyperbilirubinemia, Management of Hyperbilirubinemia in the Newborn Infant 35 or More Weeks of Gestation. Pediatrics. 2004 ;114(1): 297

5. Ekteish A F, Daoud A, Rimawi H, Kakish K, Abu-Heija A. Neonatal exchange transfusion: a Jordanian experience.Ann Trop Paediatr. 2000; 20(1):57-60.

6. Begum S, Baki MA, Kundu G, Islam I, Talukdar, MK, Fatema K, Exchange Transfusion: Indication and Adverse Effect. Bangladesh J child health 2012; 36 (1): $16-19$

7. Jackson J C, Adverse Events Associated With Exchange Transfusion in Healthy and ill Newborns. Pediatrics 1997;99;e7

8. Weisz B, Belson A, Milbauer B, Reif S. Complications of exchange transfusion in term and preterm newborns. Harefuah. $1996 ; 130(3): 170-3$.

9. Patra K, ,Amy Storfer-Isser A, Siner B, Moore J, Hack M, Adverse events associated with neonatal exchange transfusion in the 1990s. The Journal of Pediatrics.2004;144 ( 5) :626-631
10. Diwakar KK.Neonatal hyperbilirubinemia-A continuing saga. Indian Journal of Practical Pediatrics. 2005; 7(4): 274

11. Dikshit SK, Gupta PK. Exchange transfusion in neonatal hyperbilirubinemia. Indian Pediatr. 1989;26:1139-1145

12. Roland C. Ibekwe, MaryAnn U. Ibekwe, ${ }^{1}$ and Vivian U. Muoneke Outcome of Exchange Blood Transfusions Done for Neonatal Jaundice in Abakaliki, South Eastern Nigeria. J Clin Neonatol. 2012 ; 1(1): 34-37.

13. William J. Keenan, Kathy Kazmaier Novak, James M. Sutherland, Dolores A. Bryla and Karen L. Fetterly,Morbidity and mortality associated with exchange transfusion Pediatrics. 1985;75:417

14. Jackson J C. Adverse events associated with exchange transfusion in healthy and ill newborns. Pediatrics 1997;99:e7

15. Badlee $Z$ Exchange transfusion in neonatal hyperbilirubinaemia: experience in Isfahan, Iran. Singapore Med J 2007; 48(5): 421-3.

16. Laurie A. Steiner, Matthew J. Bizzarro, Richard A. Ehrenkranz and Patrick G.A Decline in the Frequency of Neonatal Exchange Transfusions and Its Effect onExchange-Related Morbidity and Mortality.Pediatrics. 2007;120:27

17. Boggs TR, Westphal MC. Mortality of exchange transfusion. Pediatrics.1960;26:745-755

18. Weldon VV, Odel GB. Mortality risk of exchange transfusion. Pediatrics. 1968; $41: 797-801$

19. Hovi L, Siimes MA. Exchange transfusion with fresh heparinized blood is a safe procedure. Acta Paediatr Scand. 1985;74:360-365

20. Keenan WJ, Novak KK, Sutherland JM, Bryla DA, Fetterly KL. Morbidity and mortality associated with exchange transfusion. Pediatrics. 1985; 75(suppl):422-426 